\title{
Simulation in Canadian postgraduate emergency medicine training - a national survey
}

\author{
Evan Russell, MSc*; Andrew Koch Hall, MD, MMEd ${ }^{\dagger}$; Carly Hagel, MD ${ }^{\dagger}$; Andrew Petrosoniak, MD, MSc ${ }^{\S}$; \\ Jeffrey Damon Dagnone, MD, MMEd ${ }^{\dagger}$; Daniel Howes, $\mathrm{MD}^{\dagger \ddagger}$
}

\section{ABSTRACT}

Objectives: Simulation-based education (SBE) is an important training strategy in emergency medicine (EM) postgraduate programs. This study sought to characterize the use of simulation in FRCPC-EM residency programs across Canada. Methods: A national survey was administered to residents and knowledgeable program representatives (PRs) at all Canadian FRCPC-EM programs. Survey question themes included simulation program characteristics, the frequency of resident participation, the location and administration of $\mathrm{SBE}$, institutional barriers, interprofessional involvement, content, assessment strategies, and attitudes about SBE.

Results: Resident and PR response rates were 63\% (203/321) and $100 \%(16 / 16)$, respectively. Residents reported a median of 20 (range $0-150$ ) hours of annual simulation training, with $52 \%$ of residents indicating that the time dedicated to simulation training met their needs. PRs reported the frequency of SBE sessions ranging from weekly to every 6 months, with 15 (94\%) programs having an established simulation curriculum. Two (13\%) of the programs used simulation for resident assessment, although 15 (94\%) of PRs indicated that they would be comfortable with simulationbased assessment. The most common PR-identified barriers to administering simulation were a lack of protected faculty time $(75 \%)$ and a lack of faculty experience with simulation (56\%). Interprofessional involvement in simulation was strongly valued by both residents and PRs.

Conclusions: SBE is frequently used by Canadian FRCPC-EM residency programs. However, there exists considerable variability in the structure, frequency, and timing of simulation-based activities. As programs transition to competency-based medical education, national organizations and collaborations should consider the variability in how SBE is administered.

\section{RÉSUMÉ}

Objectif: La formation par simulation (FS) constitue un élément important de l'apprentissage dans les programmes d'études de cycle supérieur en médecine d'urgence (MU).
L'étude décrite ici visait à caractériser le recours à la simulation dans les programmes de résidence du Collège royal des médecins et chirurgiens du Canada en MU, partout au Canada.

Méthode: Une enquête nationale a été menée parmi les résidents et parmi les représentants des programmes (RP) de MU du Collège royal, bien au fait de la situation, partout au Canada. Différents thèmes ont été abordés dans le questionnaire d'enquête, soit les caractéristiques des programmes de simulation, la fréquence de la participation des résidents, le lieu et le déroulement des séances de FS, les obstacles liés aux établissements, la participation interprofessionnelle, le contenu, les formes d'évaluation et les attitudes à l'égard de la FS.

Résultats: Le taux de réponse parmi les résidents et les RP s'est élevé respectivement à $63 \%(203 / 321)$ et à $100 \%(16 / 16)$. Les résidents ont fait état d'une médiane de 20 heures (plage : 0-150) de FS au cours d'une année, et $52 \%$ d'entre eux ont indiqué que le temps consacré à la FS répondait à leurs besoins. Quant aux RP, ils ont fait état d'une fréquence très variable des séances, allant d'hebdomadaire à semestrielle, et des activités de FS étaient prévues dans le curriculum de 15 programmes (94\%). Dans deux d'entre eux (13\%), d'ailleurs, la simulation servait à l'évaluation des résidents; cependant, 15 RP (94\%) ont indiqué qu'ils se sentiraient à l'aise avec les évaluations reposant sur la simulation. Les obstacles à la FS mentionnés le plus souvent par les RP étaient le manque de temps réservé au personnel enseignant pour ce type d'activité (75\%) et le manque d'expérience du personnel enseignant en matière de simulation (56 \%). Enfin, la participation interprofessionnelle aux séances de simulation était grandement appréciée, tant par les résidents que par les RP.

Conclusions: La FS est une forme d'enseignement utilisée très souvent dans les programmes de résidence du Collège royal, en MU, au Canada. Toutefois, il existe des différences importantes quant à la structure des activités, à leur fréquence et au moment de leur tenue. Comme les programmes évoluent vers un enseignement de la médecine reposant sur les compétences, les organisations nationales et les parties qui

From the ${ }^{*}$ Queen's University School of Medicine, Kingston, ON; †Department of Emergency Medicine and $¥$ Department of Critical Care Medicine, Queen's University, Kingston, ON; and §Department of Medicine, St. Michael's Hospital, University of Toronto, Toronto, ON.

Correspondence to: Dr. Andrew Koch Hall, Department of Emergency Medicine, Queen's University, Kingston General Hospital, Victory 3, 76 Stuart Street, Kingston, ON K7L 2V7; Email: andrewkhall@gmail.com 
offrent leur collaboration devraient se pencher sur les différences qui existent entre les nombreuses formules de FS.
Keywords: emergency medicine, manikins, medical education, postgraduate, simulation, survey

\section{INTRODUCTION}

Simulation-based education (SBE) is well established in postgraduate medical education. ${ }^{1}$ In certain situations, simulation has been shown to be superior to traditional clinical education, ${ }^{2}$ and there is growing evidence showing that SBE improves patient outcomes. ${ }^{3}$ Emergency medicine (EM) training programs have particularly embraced SBE., ${ }^{4,5}$ There are several descriptions in the literature of the incorporation of SBE into postgraduate EM training programs. ${ }^{6,7} \mathrm{EM}$ residents derive many benefits from SBE as a training modality. It provides a safe, realistic environment to hone their clinical decisionmaking, technical skills, to develop their leadership and collaborative abilities, and to receive immediate feedback on their performance. ${ }^{8}$ The standardization, fidelity, and reproducibility of SBE also make it well suited for the assessment of clinical competence. ${ }^{1}$ The direct evaluation of performance through simulation-based assessment provides a unique opportunity for simultaneous evaluation of knowledge, clinical reasoning, and teamwork. ${ }^{9}$ In Canada, there has been a national call for SBE to be further integrated into existing postgraduate curricula. ${ }^{10}$ The Royal College of Physicians and Surgeons is currently implementing the CanMEDS 2015 Physician Competency Framework and the Competency By Design (CBD) initiative for all programs. ${ }^{11}$ In this transition, simulation will likely play an even more important role as the assessment of clinical expertise moves toward competency-based assessment. ${ }^{12}$

Over the past decade, there has been steady growth in the adoption of simulation within EM residency training. A survey of 156 U.S. EM residency programs conducted in 2003 found that the majority of institutions lacked a formal simulation curriculum. ${ }^{13}$ A subsequent study conducted in 2008 found that the majority of U.S. EM residency programs used over 10 hours per year of SBE in their curricula. ${ }^{14}$

A more complete understanding of how SBE is delivered in Canadian EM training programs will aid in establishing norms and may offer both insights on best practice and barriers to implementation. The purpose of this study was to establish the current state of SBE in Canadian FRCPC-EM training programs using structured surveys for learners and educators.

\section{METHODS}

From October 2015 to January 2016, we conducted two national surveys assessing the use of SBE in all Canadian FRCPC-EM programs. The study was approved by the Queen's Health Sciences Research Ethics Board (\#6016057).

\section{Study populations}

All 16 Canadian FRCPC-EM programs were surveyed, including the three separate geographic sites that exist at the University of British Columbia. At each program, a program representative $(\mathrm{PR})$ and all residents in their second to fifth postgraduate year (PGY2-5) were surveyed. The PR was the FRCPC-EM Program Director, the Assistant Program Director, or the Simulation Director at that site.

\section{Survey development}

Surveys were designed to capture both $\mathrm{PR}$ and resident perspectives. This occurred in three phases. Phase one consisted of a literature review using the MEDLINE and PubMed databases to look for surveys of simulation activities in EM residencies. Two relevant articles were identified. ${ }^{13,14}$ Study investigators developed survey questions using the topics and themes identified from a detailed review of each article, including the general characteristics of institutional simulation programs, the frequency of resident participation in simulation, the location and administration of simulation facilities, and perceived barriers to SBE implementation. Surveys for both PRs and residents contained dichotomous, Likert-type, rank-order, and open-ended questions. ${ }^{15}$

In phase two, study investigators convened to review the aforementioned themes and broaden the question list. Most study investigators have pursued advanced training in SBE (Harvard-Macy Institute, MA; Kingston Resuscitation Institute, ON) or in medical education in the form of a master's degree in Medical Education (University of Dundee, Scotland) or Medical Education Leadership (University of New England, ME). Question topics included the use of SBE for interprofessional training, the role of SBE for 
resident performance assessment, a review of appropriate clinical content for SBE, and comfort participating in SBE.

The third phase consisted of a piloting and review process. The survey was piloted at a single institution (Queen's University) among 12 non-EM residents and an FRCPC program director for comprehension and evidence of content-validity. An additional review was performed by an external EM education scholar for a final review and feedback.

\section{Survey administration}

A modified Dillman approach was used to recruit both residents and PRs. ${ }^{16}$ All potential participants received a letter of information prior to their enrolment in the study. Both residents and PRs were informed that personal and institution-specific data provided would be de-identified.

The PR survey (Online Appendix A) was conducted via telephone by one of two study investigators $(\mathrm{CH}$ or $\mathrm{AH})$. Using a semi-structured format, an interviewer read the survey questions to PR participants with clarification provided as needed. PR responses were transcribed by the interviewer and then collated in Excel.

The resident survey (Online Appendix B) was offered in both paper and online versions. Prior to administration of the resident surveys, a resident champion was identified at each site. Paper copies were mailed to each site champion to distribute to all eligible residents. Completed hard copies were returned via prepaid, preaddressed packages. The online version was administered through an institutional subscription with fluidsurveys. com. Resident champions forwarded reminder emails to their fellow residents with a link to the online version of the survey at 2 and 3 weeks following the initial paper administration.

\section{Analysis}

Descriptive statistics were used to calculate rates and averages. Data sets were assessed for normality using the Shapiro-Wilk test. Normally distributed data are reported as mean \pm standard deviation, and non-normally distributed data are reported as median (range). Responses to Likert questions were reported as the percentage of respondents who selected a particular response. Spearman rho analyses or Mann-Whitney $U$ tests were used to compare reported hours of simulation training with other survey responses. Because this survey asked residents to recall the last 1 year of their training, residents in the first year of training were not included. Junior residents were defined as PGY2/3 respondents, and senior residents were defined as PGY4/5 respondents. For all statistical analyses, $p \leq 0.05$ was considered significant.

\section{RESULTS}

\section{Demographics}

The resident and PR response rates were 63\% (203/ $321)$ and $100 \%(16 / 16)$, respectively. Resident response rates declined with increasing postgraduate year, with $77 \%(64 / 83)$ in the PGY2 cohort, $62 \%(51 / 82)$ in the PGY3 cohort, 54\% (42/78) in the PGY4 cohort, and $33 \%(26 / 78)$ in the PGY5 cohort. Additionally, 13 residents chose to not indicate their postgraduate year. Across institutions, resident response rates ranged from $16 \%-94 \%$.

\section{Program characteristics}

Residency program statistics are summarized in Table 1. Based on PR reported data, all residency programs offer both manikin-based and task-trainer simulation modalities. Resident-reported exposure to both manikinbased and task trainer-based simulation was $99 \%$ and $91 \%$, respectively. An established simulation curriculum existed at $94 \%$ of programs, with $19 \%$ of programs reporting that SBE scenarios were temporally linked to topics that were taught in the core curriculum. The frequency of simulation training sessions ranged from weekly to every 6 months, with most programs holding sessions every 1 to 2 months. Simulation-based assessment was used in $13 \%$ of the programs, although $94 \%$ of PRs indicated that they would be comfortable with incorporating simulation-based resident assessment.

\section{Volume and frequency of simulation training}

According to PR estimates, the mean amount of annual simulation training was $42 \pm 26$ hours with considerable variability across programs (Figure 1). PRs reported an average of 4 hours of SBE per month (range of 0.5 to 8 hours). Thirty-seven percent of PRs indicated that their residents continued to participate in EMbased simulations during off-service rotations. Residents 


\begin{tabular}{|lc|}
\hline Table 1. Residency program characteristics & \\
\hline & Programs, $\mathrm{n}(\%)$ \\
\hline Use simulation of any type & $16(100)$ \\
$\quad$ Manikins & $16(100)$ \\
Partial task trainers & $16(100)$ \\
Standardized patients & $6(37)$ \\
Established formal simulation curriculum & $15(94)$ \\
Frequency of simulation activities: & \\
1-2 Weeks & $4(25)$ \\
1-2 Months & $8(50)$ \\
3-6 Months & $1(6)$ \\
6-12 Months & $3(19)$ \\
Simulation curriculum topics temporally linked & $3(19)$ \\
to core curriculum topics & \\
Simulation used as a structured means of & $2(13)$ \\
either formative or summative assessment & \\
Management of manikin-based simulator: & 13 \\
School of Medicine/University & 2 \\
Private not-for-profit (e.g., hospital) & 2 \\
Private for-profit & $4(56)$ \\
Department of EM & $6(37)$ \\
Other & \\
Simulation programs that conduct & \\
interprofessional simulation with the & \\
following health-care providers: & \\
Registered nurses (RNs) & \\
Respiratory therapists (RTs) & \\
Paramedics & \\
\hline
\end{tabular}

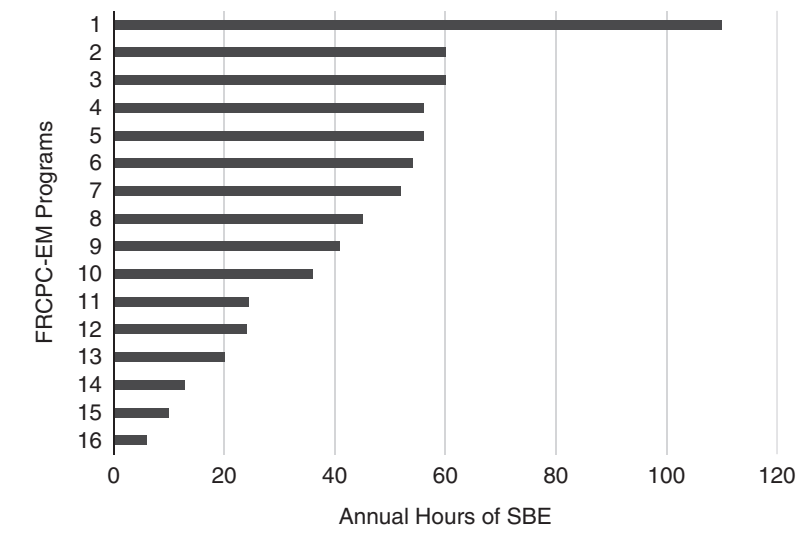

Figure 1. PR-reported total annual hours of simulation training by program. Programs that have been de-identified are listed in descending order of annual amount of SBE.

reported participating in significantly more SBE per month when on-service (EM rotations), as compared to when they were off-service (3 [0-40] v. $1.5[0-20]$ hours, $p<0.0001)$. PR-reported annual volume of SBE was significantly greater than resident-reported volumes (42.9 [6-110] v. 20 hours [0-150] hours, $p=0.017$ ); however, the reported volumes of monthly SBE were not significantly different between PRs and residents (4 [0.5-8] v. $3[0-40]$ hours, $p=0.19$ ). Senior residents reported spending significantly less time per month in SBE than junior residents (2 [0-17] v. $3[0-40]$ hours, $p<0.05)$.

Resident- and PR-reported level of comfort and perceived utility of SBE are summarized in Table 2, Q1-4. Of the resident respondents, $87 \%$ indicated comfort with SBE, $60 \%$ were comfortable with using SBE for assessment, and $54 \%$ indicated that their programs' current SBE was meeting their educational needs. In addition, $87 \%$ of residents indicated that SBE has improved their abilities to care for real patients.

\section{Location of simulation administration}

The PR-reported locations of SBE administration, as reported in Figure 2, are highly variable, with some programs solely using a hospital simulation lab, others using only an off-site simulation facility, and in situ simulation (ISS) utilization occupying from zero to $50 \%$ of programs' SBE curricula. Aggregate resident responses reported that the most common location for SBE was a hospital-based simulation lab (56.1\%), followed by an off-site simulation lab (26.6\%), and then ISS within the emergency department (ED) (14.6\%).

Resident responses to questions pertaining to ISS and unannounced simulation were variable (see Table 2, Q7-9). ISS was the preferred method of SBE for 35\% of residents. A minority (20\%) of residents preferred surprise/unannounced SBE compared to scheduled sessions. However, $49 \%$ of residents appreciated the potential educational value of surprise simulations. Residents were more likely to report preference for surprise simulation when they agreed that it had educational benefit $\left(\mathrm{r}^{2}=0.48, p<0.001\right)$.

\section{Barriers to simulation}

PR-reported barriers to SBE at their institutions are reported in Table 3. The most common barriers were lack of protected faculty time (75\%) and lack of faculty experience with simulation (56\%). These were also identified as the most challenging barriers to overcome.

\section{Simulation content}

Over $95 \%$ of resident respondents reported having participated in simulation training involving airway emergencies, shock, adult cardiac arrest, pediatric 
Table 2. The mean percentages of resident and PR responses to questions about comfort in a simulation environment and how SBE is administered. (For each question, resident data reflect answers to the aforementioned statement [a], and PR data reflect answers to the below listed statement [b])

\section{Question}

1a I feel comfortable participating in simulation-based educational activities

$1 \mathrm{~b}$ You are comfortable with your residents participating in simulation-based educational activities.

2a I feel comfortable being examined in the simulation environment.

$2 \mathrm{~b}$ You are comfortable with your residents being assessed in the simulation environment.

3a The time dedicated to simulation-based activities during my residency meets my educational needs.

3b The time dedicated to simulation-based activities during residency meets your residents' educational needs.

4a My ability to care for real patients is improved because I have practiced similar situations through simulation training.

4b Your residents' abilities to care for real patients is improved because they have practiced similar situations through simulation training.

$5 a \quad$ I find the addition of multidisciplinary team members (RNs, RTs, other) helpful in simulation training.

$5 \mathrm{~b}$ The addition of multidisciplinary team members (RNs, RTs, other) is helpful in your residents' simulation training.

6a I would like greater multidisciplinary team member (RNs, RTs, other) participation in simulation training.

$6 \mathrm{~b}$ You would like great multidisciplinary team member (RNs, RTs, other) participation in simulation training with your residents.

7a I prefer simulation that is performed in situ (in the ED) compared to that performed in a simulation lab.

7b You prefer your residents to have simulation that is performed in situ (in the ED) compared to that performed in a simulation lab.

8 a I prefer simulation that is unannounced/a surprise to that which is scheduled.

$8 \mathrm{~b}$ You prefer your residents to have simulation that is unannounced/a surprise to that which is scheduled.

9a Simulation that is unannounced/surprise to that which is scheduled offers a clinically useful educational experience.

9b Simulation that is unannounced/a surprise to that which is scheduled offers your residents a clinically useful educational experience.

$\begin{array}{rrr}\text { Agree } & \text { Neutral } & \text { Disagree } \\ 87 \% & 9 \% & 4 \% \\ 100 \% & 0 \% & 0 \% \\ 60 \% & 24 \% & 16 \% \\ 88 \% & 6 \% & 6 \% \\ 54 \% & 22 \% & 24 \% \\ 69 \% & 6 \% & 25 \% \\ 87 \% & 12 \% & 2 \% \\ & & \\ 100 \% & 0 \% & 0 \% \\ & & \\ 82 \% & 15 \% & 3 \% \\ 100 \% & 0 \% & 0 \% \\ & & \\ 77 \% & 20 \% & 3 \% \\ 88 \% & 6 \% & 6 \% \\ & & \\ 35 \% & 55 \% & 10 \% \\ 31 \% & 50 \% & 19 \% \\ & & \\ 20 \% & 46 \% & 33 \% \\ 19 \% & 31 \% & 50 \% \\ 49 \% & 38 \% & 13 \% \\ 44 \% & 44 \% & 13 \% \\ & & \\ & & \end{array}$

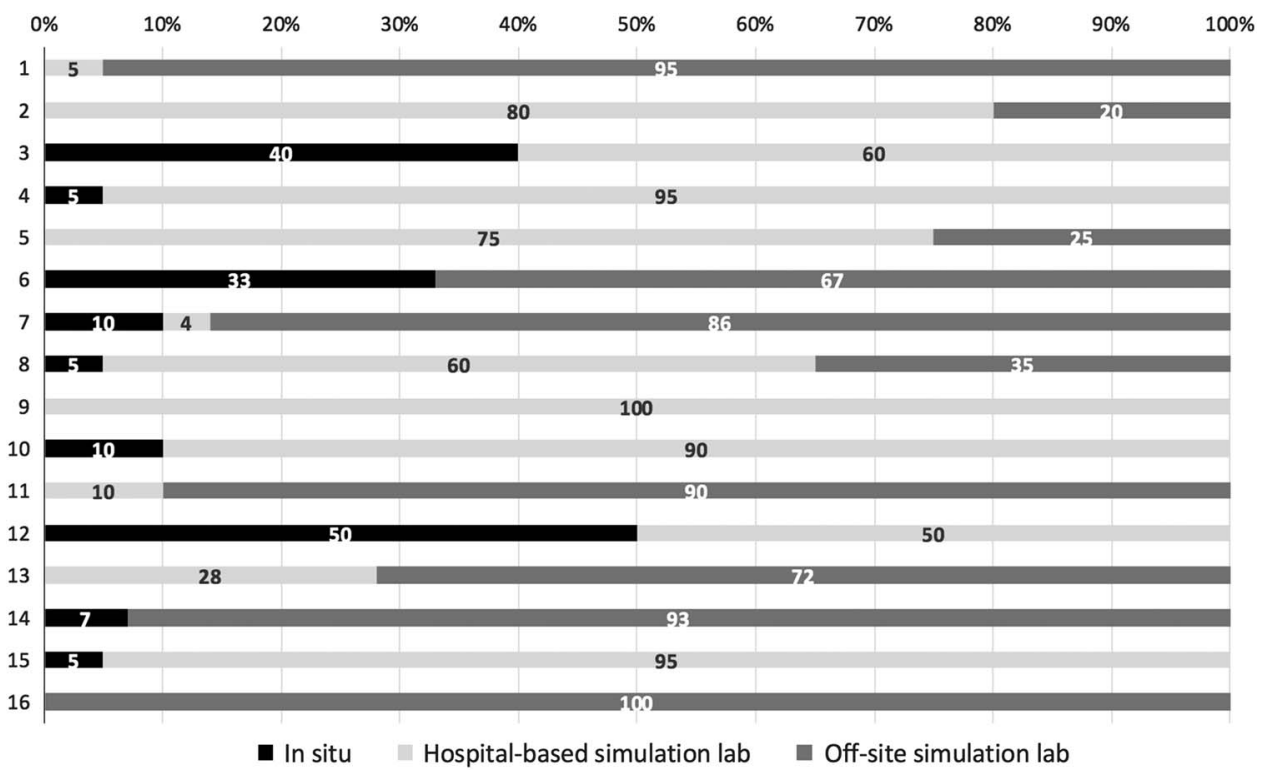

Figure 2. Institution-specific percentages of where SBE is occurring. Please note that the numbers on the $y$-axis correspond to the de-identified program numbers listed in Figure 1.

resuscitations, cardiac emergencies, and respiratory emergencies during their residency. Residents reported that some clinical subjects were less represented in their SBE curricula, with $17 \%-32 \%$ of residents indicating that they had received insufficient simulation exposure to pediatric resuscitation, to neonatal resuscitation, and to emergencies that were vascular, gastrointestinal, neurological, endocrine/metabolic, infectious, or obstetrical in nature. 
Resident responses pertaining to the amount of SBE time dedicated to specific clinical presentations are presented in Figure 3.

\section{Interprofessional involvement}

Interprofessional participation in the SBE program varied across institutions. Of the PR-reported data, 15 (94\%) residency programs have involved nursing staff, $9(56 \%)$ have involved respiratory therapists, and $6(37 \%)$ have involved paramedics in their simulation programs. Residents reported that other health care professionals are present in $41 \%$ of their total simulation sessions. A breakdown of the specific professionals involved in resident-reported interprofessional simulations is presented in Figure 4. Of the resident respondents, $82 \%$ indicated that interprofessional involvement was

\begin{tabular}{|lc|}
\hline Table 3. PR-reported barriers to SBE \\
\hline & Programs, n (\%) \\
\hline Lack of faculty time & $12(75)$ \\
Faculty inexperience & $9(56)$ \\
Cost & $7(44)$ \\
Lack of access to equipment & $6(37)$ \\
Lack of protected time within a curriculum & $5(31)$ \\
Faculty disinterest & $4(25)$ \\
Resident disinterest & $1(6)$
\end{tabular}

helpful in their residency training, and 77\% indicated a desire for more interprofessional involvement. Residentreported agreement on the utility of interprofessional involvement in simulation was significantly correlated with a desire for more interprofessional involvement in $\operatorname{SBE}\left(\mathrm{r}^{2}=0.55, p<0.0001\right)$.

\section{DISCUSSION}

\section{Volume and frequency of simulation training}

The annual volume and frequency of SBE training in Canadian EM residency programs are highly variable. Whereas some programs offer weekly simulation rounds for both of their junior and senior residents, other programs provide a simulation series once or twice a year for their residents. We noted that the estimated monthly volume of SBE was concordant between PRs and residents. However, PR estimates of annual hours of SBE training were significantly higher than resident estimates. We hypothesize that PR responses may not have factored in the variable attendance of residents due to off-service training experiences, post-night shifts, or vacation.

There is also variability in the experience of junior versus senior residents, with senior residents reporting 1 less hour of simulation per month. This may reflect a

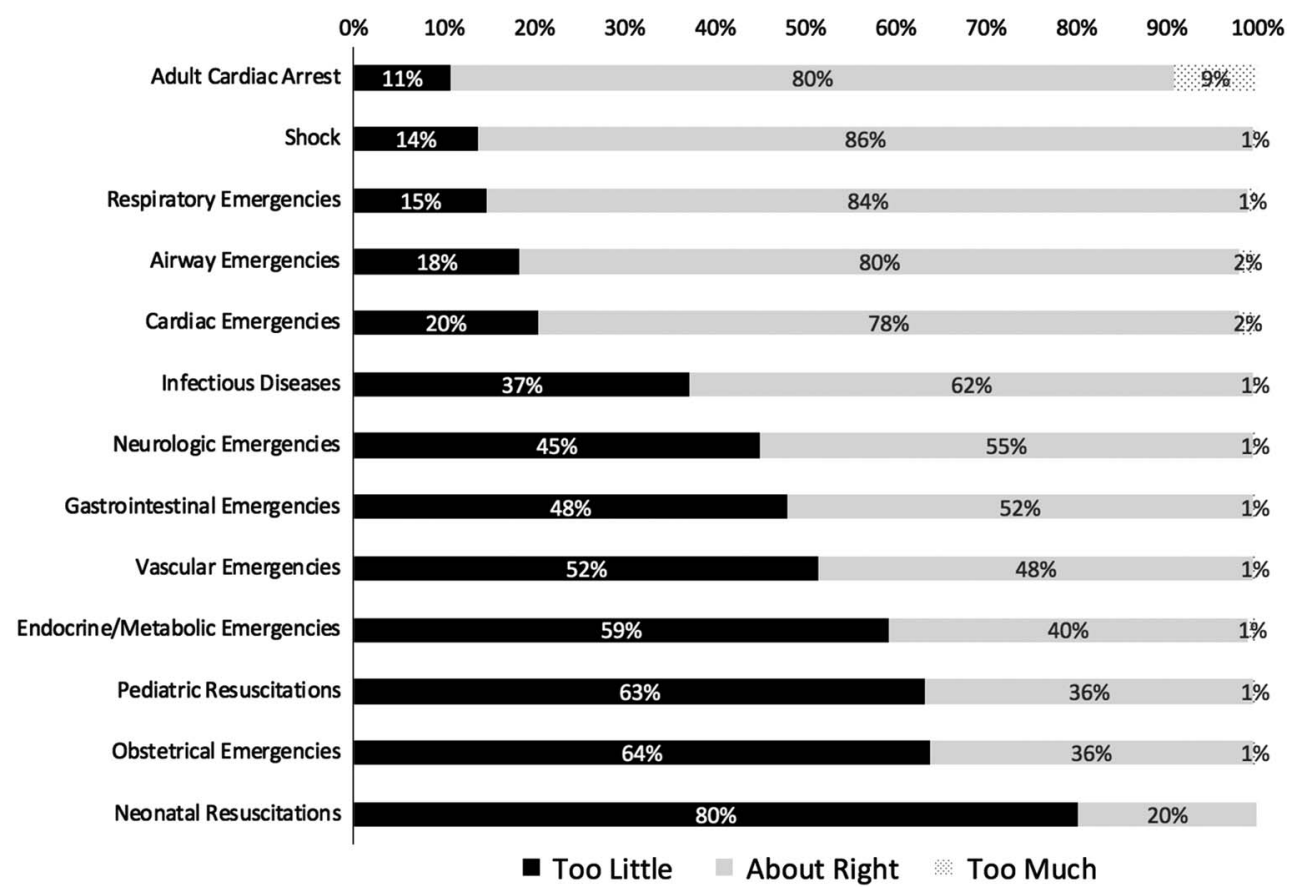

Figure 3 . Resident attitudes on the amount of time that is being dedicated to specific clinical presentations in their SBE. 

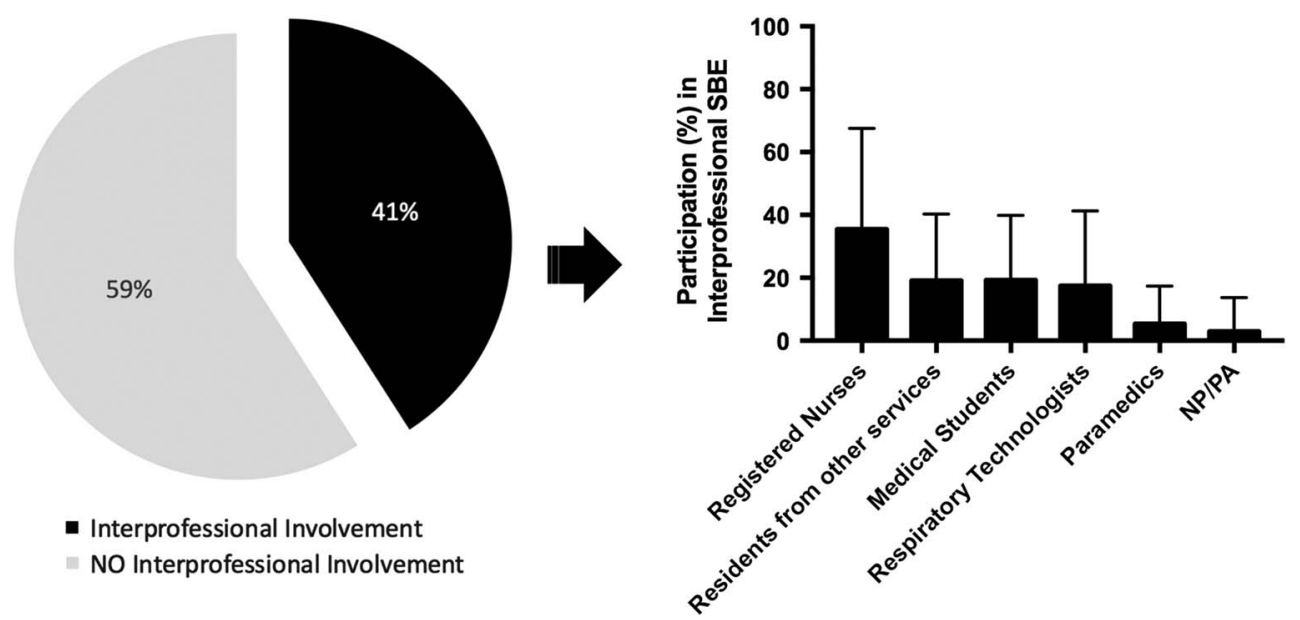

Figure 4. Resident-reported percentages of how commonly their SBE has interprofessional involvement (left). Of their SBE with interprofessional involvement, a breakdown of how commonly allied health professions are represented in their training is shown on the right.

widespread provision of SBE for juniors in basic resuscitation and procedural skills and less frequent teaching of more complicated senior level SBE, increased elective time in senior years, or an overall increase in how much simulation is being offered by programs each year. Stable gains in procedural competence have been demonstrated in as little as 8 hours of $\mathrm{SBE},{ }^{17}$ so this difference, if true, is likely educationally relevant.

Many residents and PRs indicated that their local simulation programs do not meet the educational needs of residents. The vast majority of residents expressed comfort participating in simulation and, perhaps more importantly, felt that their experience with SBE improved their ability to care for patients in the clinical setting. This finding is consistent with other studies that have demonstrated similar utility for simulation as a tool for deliberate practice and competencybased training. ${ }^{2,8,18,19}$ Our findings suggest that many Canadian EM residents and PRs would favour increased SBE.

\section{Location of simulation administration}

Traditionally, SBE has been implemented within an established simulation centre away from patient care. However, ISS, which occurs in the actual patient care environment, has gained popularity as can be used to facilitate interprofessional team training, ${ }^{20}$ identify threats to patient safety, ${ }^{21}$ and provide a cost-effective training location. ${ }^{22}$ Despite increased enthusiasm for ISS among educators, it remains an uncommon training strategy within Canadian EM residencies. Interestingly, most residents were neutral in their response to their preferred location for SBE (ISS v. simulation centre), potentially indicating an overall lack of familiarity with the training modality. With thoughtful planning, ISS can meet the residents' desires for increased interprofessional training, because the on-duty clinical team is easily brought together eliminating the scheduling and logistical constraints associated with a simulation centre.

The application of ISS also allows for unannounced (or surprise) sessions during an ED shift. Resident attitudes towards such sessions were generally negative or neutral, although they acknowledged the potential educational benefit that could be achieved. Although unannounced ISS has a potential role for training residents as they transition to practice, these findings indicate that educators must recognize this reluctance and ensure a safe learning environment. Our findings demonstrate considerable opportunities for growth in ISS within Canadian EM residencies as a cost-effective training strategy.

\section{Barriers to simulation}

Understanding the barriers to SBE and how these barriers evolve over time is essential to keep pace with the evolving needs of learners, programs, and institutions. We found that faculty time and training are the primary obstacles to simulation use and implementation. These findings match U.S. data, ${ }^{14}$ which no longer report funding as the main barrier. Access to both 
equipment and space is now less problematic, because most training programs and institutions have successfully created environments for SBE. Educators and administrators alike must appreciate these barriers of faculty time and training as they develop institutional strategic plans. Focused efforts to encourage faculty development in SBE may serve to decrease the reliance on the existing small group of taxed simulation educators.

The issue of increasing faculty time for participation in SBE is challenging. Most EM training programs already struggle to find funding for their hardworking faculty. Hopefully, this survey and the previously mentioned evidence supporting SBE can be leveraged locally by programs and educators to advocate for SBE, while national organizations can be called upon to encourage protected time for SBE educators.

The establishment of a Canadian EM-specific SBE working group has the potential to facilitate increased sharing of curriculum, scenarios, assessment tools, and other materials between programs. Coordinated educational programs to address faculty development offer an opportunity to leverage the strengths of more experienced centres and to share successes between centres. This could increase both the efficiency and the support of simulation educators nationally.

\section{Simulation content}

It is clear that SBE needs to be carefully integrated into educational curriculum to complement clinical education. ${ }^{1}$ Certain clinical content is more easily integrated within $\mathrm{SBE}^{23}$ and therefore more frequently taught using simulation. In our survey, almost all residents reported participating in training involving common SBE content such as cardiac arrest and airway emergencies. In fact, $9 \%$ of residents reported that they perceived adult cardiac arrest to be receiving too much attention in their SBE. This was a surprising finding, given the large body of evidence supporting the use of SBE for the teaching of adult cardiac arrest. ${ }^{24}$ Perhaps trainees do not recognize the importance of spaced repetition when practicing adult cardiac arrest algorithms, and the potential for poor skill retention and skill decay. ${ }^{25}$ Alternatively, trainees may recognize the importance of teaching cardiac arrest but think that the percentage of SBE time that it occupies detracts from other content that could be taught in its place. It is important to remember that the purpose of cardiac arrest training extends beyond effective $\mathrm{CPR}$, as it provides a medium through which to teach transferable skills such as crisis resource management and effective leadership strategies. Ultimately, the finding that multiple trainees report that cardiac arrest is being over-taught suggests that there needs to be dialogue between residents and simulation leads, at minimum.

In contrast, neonatal resuscitation and obstetrical emergencies were underrepresented within the SBE curriculum, despite a clear desire for this experience. This may reflect a lack of access to either the appropriate manikins for such scenarios or experts to deliver this SBE content. Additionally, SBE content may reflect more common ED presentations, despite the apparent benefits of SBE for uncommon or rare presentations. ${ }^{3}$ We hope that our survey findings can be used by EM programs and institutions to advocate for access to appropriate training equipment to conduct pediatric, neonatal, and obstetrical emergencies.

Moving forward, it may be reasonable to develop a list of core SBE content for EM. This content may become more apparent as we transition to competency-based medical education and deficits in clinical exposure become apparent with more rigorous tracking. Also, the national consensus on a simulation-based curriculum could be modelled after the Delphi process for establishment of a pediatric EM curriculum used by Bank et al. ${ }^{26}$

\section{Interprofessional involvement}

Interprofessional simulation training improves the real-world functioning of teams in the ED, particularly team efficiency during life-threatening emergencies. ${ }^{27}$ Interprofessional SBE can improve the residents' knowledge of other health care providers' roles, and develop communication and teamwork skills that are integral to successful resuscitation efforts. ${ }^{28,29}$ Without interprofessional colleagues alongside residents, it is difficult to train higher level competencies that involve leadership, collaboration, and crisis resource management. Respondents in this study indicated a resounding desire for increasing interprofessional involvement in their SBE activities. Although it is encouraging that $94 \%$ of programs have had nursing involvement during their simulation sessions, it is noted that other professions (respiratory therapists, paramedics) are less well represented. These data represent an opportunity for programs to advocate for increased meaningful interprofessional simulation. 


\section{LIMITATIONS}

This study's limitations predominantly relate to resident-reported data. We purposefully excluded PGY1 residents from participation in the survey. When the survey was administered, PGY1 residents had completed only 3 months of residency. The study team decided that this length of time was insufficient to provide an accurate report of their institutions' SBE.

Among eligible residents, only $63 \%$ responded, and the response rate varied considerably across institutions, with as few as $16 \%$ of residents responding from one institution. Fortunately, the site-specific resident response rates were independent of any PR-reported measures. This institutional variability in the resident response rate likely affects the validity of the mean resident-reported percentages of where $\mathrm{SBE}$ is being administered. For these results, the location of administration will be distorted to proportionally reflect how simulation is being administered at institutions that had better resident response rates.

A participation bias among residents was also noted, with a stepwise decline in the response rate with advancing postgraduate year. This finding was similar to other surveys of EM residents ${ }^{30}$ and may be due to increasing survey fatigue with advancing training or a focus on the final board certification exams, in the case of the final year residents. This may have acted to falsely inflate resident hours of reported simulation at institutions where simulation is offered to junior residents only. Furthermore, this may have distorted the reported experience and attitudes relating to simulation content, because some content is typically taught at a senior level only.

Finally, surveys were offered in English only. Although there were no concerns about the English literacy of the respondents whose first language is French, offering a French survey may have improved the response rate.

\section{CONCLUSION}

This study characterizes SBE utilization across Canadian FRCPC-EM residency programs and identifies several gaps in EM simulation delivery. These gaps should be carefully considered prior to the establishment of national consensus on the role of SBE in EM training. As each FRCPC-EM program transitions to competency-based medical education, collaborations and working groups should consider the substantial variability in the administration of SBE and the barriers that exist to further expanding its utilization.

Acknowledgements: This study was supported by an unrestricted grant from the Kingston Resuscitation Institute, Kingston, ON.

Competing interests: None declared.

\section{SUPPLEMENTARY MATERIALS}

For supplementary material/s referred to in this article, please visit https://doi.org/10.1017/cem.2017.24

\section{REFERENCES}

1. McGaghie WC, Issenberg SB, Petrusa ER, et al. A critical review of simulation-based medical education research: 2003-2009. Med Educ 2010;44(1):50-63.

2. McGaghie WC, Issenberg SB, Cohen ER, et al. Does simulation-based medical education with deliberate practice yield better results than traditional clinical education? A meta-analytic comparative review of the evidence. Acad Med 2011;86(6):706-11.

3. Orledge J, Phillips WJ, Murray WB, et al. The use of simulation in healthcare: from systems issues, to team building, to task training, to education and high stakes examinations. Curr Opin Crit Care 2012;18(4):326-32.

4. Ilgen JS, Sherbino J, Cook DA. Technology-enhanced simulation in emergency medicine: a systematic review and meta-analysis. Acad Emerg Med 2013;20(2):117-27.

5. McLaughlin S, Fitch MT, Goyal DG, et al. Simulation in graduate medical education 2008: a review for emergency medicine. Acad Emerg Med 2008;15(11):1117-29.

6. Dagnone JD, McGraw R, Howes D, et al. How we developed a comprehensive resuscitation-based simulation curriculum in emergency medicine. Med Teach 2016;38(1): 30-5.

7. Binstadt ES, Walls RM, White BA, et al. A comprehensive medical simulation education curriculum for emergency medicine residents. Ann Emerg Med 2007;49(4):495.

8. Okuda Y, Bryson EO, DeMaria S Jr, et al. The utility of simulation in medical education: what is the evidence? Mt Sinai 7 Med 2009;76(4):330-43.

9. Epstein RM. Assessment in medical education.[see comment]. N Engl 7 Med 2007;356(4):387-96.

10. LeBlanc VR, McNaughton N, Brydges R, et al. Simulation in postgraduate medical education. Members of the FMEC PG consortium; 2011.

11. Frank JR, Snell LS, Sherbino J. CanMEDS 2015 physician competency framework. Ottawa: Royal College of Physicians and Surgeons of Canada; 2015.

12. Boursicot K, Etheridge L, Setna Z, et al. Performance in assessment: consensus statement and recommendations from the Ottawa conference. Med Teach 2011;33(5): $370-83$. 
13. McLaughlin SA, Bond W, Promes S, et al. The status of human simulation training in emergency medicine residency programs. Simul Healthc 2006;1:18-21.

14. Okuda Y, Bond W, Bonfante G, et al. National growth in simulation training within emergency medicine residency programs, 2003-2008. Acad Emerg Med 2008;15(11):1113-6.

15. Woodward CA. Questionnaire construction and question writing for research in medical education. Med Educ 1988; 22(4):345-63.

16. Dillman DA SJD, Christian LM. Mail and Internet surveys: the tailored design method. 3rd ed. New York: John Wiley \& Sons; 2009.

17. Langhan TS, Rigby IJ, Walker IW, et al. Simulation-based training in critical resuscitation procedures improves residents' competence. C7EM 2009;11(6):535-9.

18. McGraw R, Chaplin T, McKaigney C, et al. Development and evaluation of a simulation-based curriculum for ultrasound-guided central venous catheterization. CFEM 2016;18(6):405-13.

19. Wayne DB, Didwania A, Feinglass J, et al. Simulation-based education improves quality of care during cardiac arrest team responses at an academic teaching hospital: a casecontrol study. Chest 2008;133(1):56-61.

20. Knight LJ, Gabhart JM, Earnest KS, et al. Improving code team performance and survival outcomes: implementation of pediatric resuscitation team training. Crit Care Med 2014;42(2):243-51.

21. Wheeler DS, Geis G, Mack EH, et al. High-reliability emergency response teams in the hospital: improving quality and safety using in situ simulation training. BMF Qual Saf 2013;22(6):507-14.
22. Calhoun $\mathrm{AW}$, Boone $\mathrm{MC}$, Peterson $\mathrm{EB}$, et al. Integrated in-situ simulation using redirected faculty educational time to minimize costs: a feasibility study. Simul Healthc 2011;6(6): $337-44$.

23. Khan K, Pattison T, Sherwood M. Simulation in medical education. Med Teach 2011;33(1):1-3.

24. Cheng A, Lockey A, Bhanji F, et al. The use of high-fidelity manikins for advanced life support training - a systematic review and meta-analysis. Resuscitation 2015;93:142-9.

25. Mancini ME, Soar J, Bhanji F, et al. Part 12: education, implementation, and teams: 2010 International Consensus on Cardiopulmonary Resuscitation and Emergency Cardiovascular Care Science With Treatment Recommendations. Circulation 2010;122(16 Suppl 2):S539-81.

26. Bank I, Cheng A, McLeod P, et al. Determining content for a simulation-based curriculum in pediatric emergency medicine: results from a national Delphi process. CFEM 2015;17(6):662-9.

27. Capella J, Smith S, Philp A, et al. Teamwork training improves the clinical care of trauma patients. I Surg Educ 2010;67(6):439-43.

28. Dagnone JD, McGraw RC, Pulling CA, et al. Interprofessional resuscitation rounds: a teamwork approach to ACLS education. Med Teach 2008;30(2):e49-54.

29. Watters C, Reedy G, Ross A, et al. Does interprofessional simulation increase self-efficacy: a comparative study. BMF Open 2015;5(1):e005472.

30. Petrosoniak A, Herold J, Woolfrey K. Emergency medicine procedural skills: what are residents missing? CFEM 2013; 15(4):241-8. 